\title{
The Relationship between Vocabulary Mastery and Reading Performance
}

\author{
Yani Adyawardhani \\ English Department, Politeknik Negeri Bandung, Indonesia \\ Email: yani.adya@polban.ac.id
}

\begin{abstract}
This study investigates the relationship between students' vocabulary knowledge and their reading performance. It aims at finding out whether vocabulary knowledge correlates with reading performance. The data was taken from final semester examination marks of Vocabulary 2 and Reading 2 subjects of 30 second semester students studying English, which was analyzed using Pearson correlation formula. The result shows that there is a slight correlation between the two subjects. Some possible causes of this result and some other educational implications are also discussed.
\end{abstract}

Keywords: reading and vocabulary; the relationship between vocabulary and reading; vocabulary; reading

\section{Introduction}

Reading, in essence, is a process of identifying letters, words, sentences which are coordinated into some kind of meaning. Many researches are carried out to justify this relationship (.......). Students studying English learn these as two separate subjects that support the success of each other. Research on vocabulary and reading, specifically in the Polban context, is rare; therefore, this study tries to find the correlation between the knowledge of vocabulary and reading English texts done by English department students of PoliteknikNegeri Bandung (Polban).

In this study program, vocabulary is offered in two semesters, while reading is offered in three semesters as separate subjects. Reading is continued in later semesters as integrated subjects in Presentation, Essay Writing, and Seminars. These two subjects may correlate with each other; however, two different teachers are responsible for the teaching of them. Taking into account their different teaching strategies and learning materials employed, there may be differences in the performance results. Therefore, it may be significant to find out whether the two subjects are actually correlated to each other, as they should be, or they may not be correlated as they are planned and implemented by two different teachers. The results of the study may contribute to the improvement of the teaching and learning process. 


\section{Literature Review}

In a broader context, vocabulary knowledge influences the language use (Mehring, 2005) and fundamental in L2 learning (Folse, 2004 in Larrotta, 2011) in a way that having knowledge of vocabulary makes language use possible, including reading, which in turn helps increase vocabulary knowledge (Nation \&Waring, 1997 in Mehring, 2005). Specifically, vocabulary knowledge may determine the quality of listening, reading, speaking, and writing (Mokhtar et.al., 2010 in Larrotta, 2011). Further, vocabulary building is an important aspect in academic success (Nation \&Waring, 1997 in Mehring, 2005) which is determined by the ability to read (Krashen, 2013). As all communication contexts are words and sentences, vocabulary/lexical knowledge becomes central to communicative competence and to the acquisition of language, especially foreign and second languages; the lack of it may be an obstacle to learning (AlQahtani, 2015). The success of academic performance in some way depends on communicative competence which mainly supported by the ability to read and write. Reading needs an ability to recognize and understand words and writing partly makes use of knowledge and information from the reading. Vocabulary building and mastery becomes fundamental in this respect.

Recognizing the meaning of words is important in the process of reading. Reading process is believed to be the integrated use of four cuing systems, the graphophonic, the syntactic, the semantic and the pragmatic (Purcell-Gates, 1997; Burkhour, (1999) which occur simultaneously. It is a process when letter and word recognition or the physical print of letters and words, is carried out at the same time as comprehension resulting from background knowledge and experience. Thus, key to the reading process is being able to identify the words and comprehension. Reading is a disaster if readers are unable to coordinate these systems. Vocabulary knowledge is, then, fundamental to the success of reading comprehension as it is a major component of reading, and, therefore, important in reading and texts comprehension (Butler, et.al., 2010).

Mehring (2005) mentioned several studies that identify the relationship between vocabulary and reading. From earlier studies, such as Thorndike (1973 in Mehring, 2005), Stanovich (1986 in Mehring, 2005) to relatively recent studies, such as Wagner, Muse, and Tannenbaum (2007 in Mehring, 2005), Bienmiller (2005 in Mehring, 2005), droop \&Verhoeven (2003 in Mehring, 2005)all show that there is a strong, causal relationship between vocabulary and reading. As Mehring (2005:266) reports that the “...the vocabulary growth leads to improved reading reading comprehension, and amount of reading leads to 
vocabulary growth...". Another study (Block \&Mangieri (2006) sees the importance of vocabulary learning that enhances the growth and development of comprehension in reading. In L2 context, Zhang \&Suaini bin Annual (2008) found that there is a relationship between students' vocabulary knowledge and reading comprehension; while Krashen (1984 in Larrotta, 2011) found out that proficient L2 learners seem to acquire much of their vocabulary from their reading.

Other studies see specifically on aspects such as depth, context, word acquisition, etc. Browne (2003) found out that intensive reading, as opposed to extensive reading, leads to the increase of number of words but at a shallower depth. Yet, Qian (2002) argues, from the result of his study, that academic performance is influenced by both vocabulary size and vocabulary depth. Some studies show that learners' vocabulary learning and retention is done through the use of example sentences that give them the contexts of language use (Baicheng, 2009 in Larrotta, 2011).This is supported by Nagy (1988) who asserted that to understand texts readers need to have an in-depth vocabulary knowledge.

These studies show that vocabulary learning is best done in meaningful contexts, the context of the target language that learners will use. As vocabulary knowledge is important in reading and comprehending texts, an appropriate amount of words with its meaning is necessary to comprehend different kinds of text, and, therefore, vocabulary learning is significant to texts comprehension (Butler, et.al., 2010). All these seem to agree that most ways of learning vocabulary are through meaningful contexts that are offered through reading texts. Even at the lower level of learning it is suggested that learners learn vocabulary through story-telling and reading aloud (Krashen, 2013).

However, there are some studies that do not consider contexts as significant in vocabulary learning. Qian's (1996 in Alves\&Oliviera, 2014) earlier study shows that from his study with foreign language and L2 learners vocabulary learning is best done without contexts of reading texts. This result, though, is contradicted by a more recent study (Qian, 2002) when learners read academic texts which confirms that to be successful in reading such texts need both vocabulary size and depth. Yet, another study, Glende (2013) found out that a combination of vocabulary instruction that matches the level of learners' instructional level is the best in improving learners' vocabulary knowledge.

All the studies show that vocabulary knowledge of an appropriate number is fundamental as well as significant in the success of reading performance for comprehension. Most studies stress the importance of vocabulary learning through some kind of contexts that help develop, promote and retain the words learned. 


\section{Method of Study and Data Analysis}

This study is looking into the relationship between vocabulary knowledge and reading performance. It assumes that there is no relationship between vocabulary knowledge and reading performance (null hypotheses - $\mathrm{H}_{0}$ ), and that there is an alternative assumption that there is a relationship between these two $\left(\mathrm{H}_{\mathrm{a}}\right)$. For this purpose, a correlation study is used as this technique is suitable for measuring relationship (Hatch \&Lazaraton, 1991). Specifically, it uses Pearson Product Moment correlation calculation approach.

\section{Data Collection}

The participants in this study are 30 second semester students studying English in Politeknik Negeri Bandung who have passed Vocabulary 2 and Reading 2 in the second semester. The data used were the marks of these subjects taken from the official mark sheets issued by the English Department (gained through permission).The following table presents the distribution of the marks for vocabulary and reading.

Table1. Distribution of marks in Vocabulary and Reading

\begin{tabular}{|c|c|c|}
\hline No & Reading & Vocabulary \\
\hline 1 & 82 & 63 \\
\hline 2 & 84 & 73 \\
\hline 3 & 75 & 70 \\
\hline 4 & 83 & 75 \\
\hline 5 & 84 & 85 \\
\hline 6 & 56 & 50 \\
\hline 7 & 80 & 53 \\
\hline 8 & 81 & 75 \\
\hline 9 & 58 & 77 \\
\hline 10 & 83 & 82 \\
\hline 11 & 79 & 35 \\
\hline 12 & 80 & 75 \\
\hline 13 & 53 & 55 \\
\hline 14 & 87 & 87 \\
\hline 15 & 88 & 72 \\
\hline & & \\
\hline
\end{tabular}

\begin{tabular}{|c|c|c|}
\hline No & Reading & Vocabulary \\
\hline 16 & 58 & 53 \\
\hline 17 & 72 & 43 \\
\hline 18 & 65 & 75 \\
\hline 19 & 82 & 85 \\
\hline 20 & 79 & 82 \\
\hline 21 & 64 & 78 \\
\hline 22 & 75 & 48 \\
\hline 23 & 83 & 73 \\
\hline 24 & 79 & 65 \\
\hline 25 & 84 & 75 \\
\hline 26 & 81 & 72 \\
\hline 27 & 77 & 55 \\
\hline 28 & 73 & 68 \\
\hline 29 & 74 & 58 \\
\hline 30 & 76 & 72 \\
\hline
\end{tabular}


From the distribution it is important to draw a scatter plot to see the strength and the possibility or the approximation of the relation between the two sets of variables. It must be done before the statistical calculation carried out. The following diagram shows the scatter plot of these two sets of data.

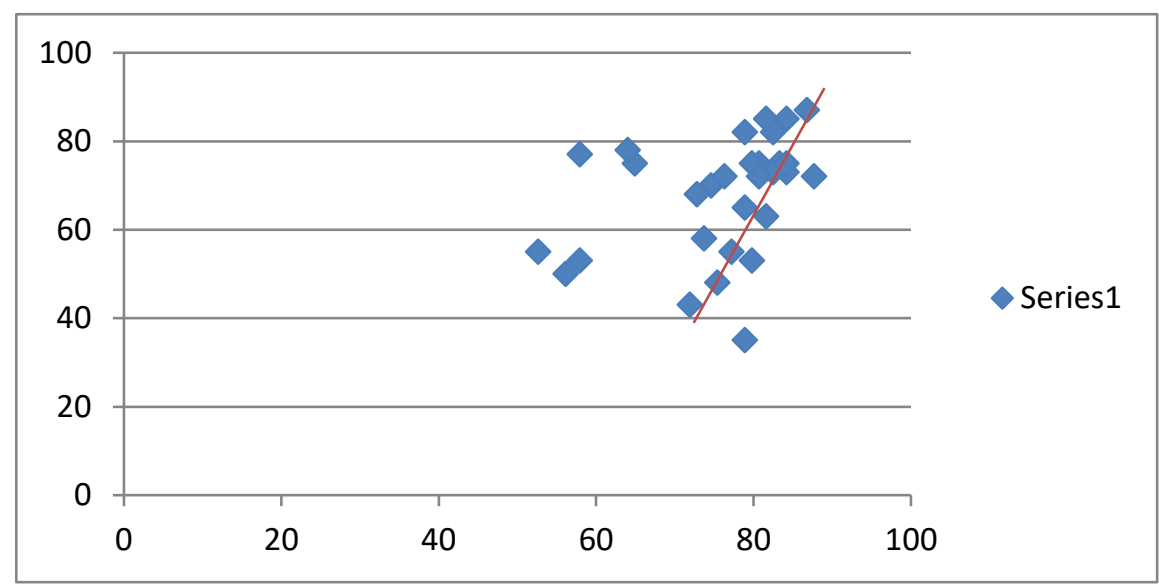

Diagram1.The scatter plot of Vocabulary and Reading

The diagram shows that there is a possibility of a relationship between the two subjects. There is a positive relationship as the dots are scattered in a pattern of a straight line. If a line is drawn (regression line), the dots are scattered more to the side of the line; this means that the relationship is not as strong as expected which will be justified by the result of the result of the correlation calculation.

\section{The calculation}

In the calculation, reading is the independent variable $(\mathrm{x})$ and vocabulary is the dependent variable (y). To find the correlation coefficient, represented by the symbol $r$, the data are calculated using Pearson formula as follows:

$\begin{array}{ll}\mathrm{N}\left(\sum \mathrm{xy}\right)-\left(\sum \mathrm{x}\right)\left(\sum \mathrm{x}\right) & \mathrm{N}=\text { the population } \\ \mathrm{r}_{\mathrm{xy}}=\sqrt{\left[\mathrm{N}\left(\sum \mathrm{x}^{2}\right)-\left(\sum \mathrm{x}\right)^{2}\right]\left[\mathrm{N}\left(\sum \mathrm{y}^{2}\right)-\left(\sum \mathrm{y}\right)^{2}\right]} \quad \begin{array}{l}\text { where } \\ \end{array} & \sum \mathrm{x}=\text { the sum total of } \mathrm{x} \\ & \sum=\text { the sum total of } \mathrm{y} \\ & \sum \mathrm{xy}=\text { the sum total }\end{array}$

The result of the calculation for $\mathrm{r}$ is 0.374 ; which is, then, checked further by calculating both sets of data to see whether they covary. The covariance value is calculated using the formula: 
$\sum(\mathrm{x}-\mathrm{x})(\mathrm{y}-\overline{\mathrm{y}})$

$\operatorname{Cov}_{x y}=\mathrm{N}-1$ wherex $=$ the mean of $\mathrm{x}$ data (reading); the mean of $\mathrm{y}$ data (vocab); $\mathrm{N}=$ the population

The computerized calculation results in the value of covariance which is 48.040 . This value shows how much the two sets covary. To have an adjusted or standardized covariance, this value is then divided by the standard deviation of each set of data using the following formulas:

$\mathrm{SD}\left(\mathrm{S}_{\mathrm{x}}\right)=\sum \mathrm{X}^{2}-\left(\sum \mathrm{X}\right)\left(\sum \mathrm{X}\right) / \mathrm{N}$
$\mathrm{N}-1$ where $\begin{aligned} & \sum \mathrm{X}=\text { the sum total of } \mathrm{X} \\ & \\ & \begin{array}{l}\sum \mathrm{Y}=\text { the sum total of } \mathrm{Y} \\ \mathrm{N}=\text { the population }\end{array}\end{aligned}$
$\mathrm{SD}\left(\mathrm{S}_{\mathrm{y}}\right)=\underline{\sum \mathrm{Y} 2-\left(\sum \mathrm{Y}\right)\left(\sum \mathrm{Y}\right) / \mathrm{N}}$ $\mathrm{N}-1$

The adjusted or standardized covariance is calculated using the formula $R_{x y}=\operatorname{Cov}_{x y}$ of which result is also the correlation coefficient.

$\mathrm{S}_{\mathrm{x}} \mathrm{S}_{\mathrm{y}}$

The calculation shows that the correlation coefficient is 0.374 which means that the correlation has taken into consideration the variance between the two sets of data, and that it also shows the same result of calculation using the Pearson formula.

\section{Results and Discussion}

The result of the coefficient correlation calculation for vocabulary and reading with the degree of freedom of $28(\mathrm{p}=0.5)$ is 0.374 , which is higher than the critical value at that level. This means that the null hypotheses $\left(\mathrm{H}_{0}\right)$ is rejected and the alternative hypotheses $\left(\mathrm{H}_{\mathrm{a}}\right)$ is accepted. In other words, there is a correlation between these two subjects. However, this correlation does not yet show how strong the association is in order that we understand the value of the relationship. The correlation coefficient of 0.374 has strength of association of 0.139 or around $14 \%$ overlap between the two sets of data. This means that there is a slight correlation between vocabulary and reading with $14 \%$ overlap; which means that only 4 students have knowledge in vocabulary that helps or correlates to their reading performance.

Although it is not as strong as expected, the study shows that there is a positive relationship between vocabulary knowledge of English words and reading English texts. We can say that there is a direct relationship (Hatch \&Lazaraton, 1991) between these two subjects, in a way that a good score in vocabulary is a predictor that the same student may 
score well in reading; and those who perform poorly in one subject also perform unsuccessfully in the other. In this study, as the result shows, a small number of students have a direct impact from this relationship; most of the students perform poorly in reading English texts as they also have a weak knowledge in the vocabulary of English words.

In the light of this result, there are some aspects which need to be accounted for, in terms of both possible causes and its implication to the teaching and learning process. When a student learns a subject in the classroom, there are several aspects influencing their success or failure in that class. Apart from the teacher him/herself, the strategy that a teacher uses in teaching and the learning materials that s/he uses partly contribute to the success or failure of students' learning.

\section{The learning strategy}

Despite the fact that there is a connection between vocabulary and reading, it does not mean that these two subjects can be integrated as one subject. In fact, some studies (e.g. Krashen, 2013; Block \&Mangieri, 2006) suggest that vocabulary learning must be done individually and directly without integrating it or teaching it as part of other subject such as inclusion in the teaching of literacy skill.

Basically, learning vocabulary means knowing words and using words (Gu, 2003); this means that vocabulary learning strategy is aimed at making students know words and be able to use them automatically in a wide range of language use. The strategy is, then, to know words and to use the words. Further, Gu (2003), mentioning the study by Ellis (1994 in Gu, 2003), states that the strategy used in learning vocabulary also depends on the focus of the learning. If the focus is on knowing words acquired, the learning strategy is on the depth of the acquisition process. If the focus is on using the words acquired, the strategy use is on frequency, recency and regularity of practice.

From the result of the study, it seems that the learning strategy that the teacher used focused more on knowing words with little practice on using the words learned. The use of reading texts in vocabulary learning provides a context where learners see how words are used and are given meanings. A learning practice that is more focused on learning individual words detaches the learners with a situation where they can see how the words they learn may have different meanings from previous understanding. Besides, the use of reading text in vocabulary learning gives also opportunities for the learners to learn how sentence structures contribute to meanings. 


\section{The learning materials}

In the strategy aspect, the learning material is as important as the strategy itself. This is because often the strategy is determined by the kind of material use in one session which may be different from other sessions.

As the focus is on which strategy to use in learning vocabulary, the kind of material selected also counts. Appropriate materials for vocabulary learning are those that are offered in contexts as they help learners to understand the words correct usage (Mehring, n.d.); these contexts in higher education (universities) are reading texts (Krashen, 2013). Whereas Baicheng (2009 in Larrotta, 2011) mentions contexts in vocabulary learning are sentences in the language learned as examples of language usage. It is claimed that this will promote learners' vocabulary learning and retention. This stresses the significance of reading texts in vocabulary learning. Further, a study (Krashen, 1984 in Larrotta, 2011) shows that in L2 vocabulary learning through reading is closely related to proficient learners.

In Polban English study program, vocabulary learning is mainly on learning words, although the contexts centered around themes or topics such as vocabulary used in business or vocabulary used to describe feelings, people, places, etc. it is possible that a lack of exposure to English texts for learning vocabulary contribute to the less significant correlation between vocabulary and reading. The practice of reading English texts only occur during the reading class. Students are exposed to English texts only for the purpose of texts comprehension which may hinder thinking about the meanings of some words.

Vocabulary learning through reading English texts has proven to be successful (Block \&Mangieri, 2005) especially in a higher level of education as the text material is a higher level than the students' level and mostly the texts are previously unread by the students. With this level of learning material, the students are forced to achieve higher than they would have been; and therefore, it is instrumental in students' vocabulary growth. They asserted that there is a linkage between vocabulary growth and reading comprehension.

We learn from the study that although vocabulary is learned for its own sake and not as part of other subject, it is not yet clear whether the strategy used really support vocabulary growth. The use of learning materials that are thematic certainly has given the learners to see the meaning of individual words in some kind of context. However, for retention purposes this material lacks opportunities for repetition, which is important to give learners a wide range of contexts where words are used. This is because the learning vocabulary is not short and simple; learners need to be exposed to many situations as vocabulary learning is a gradual 
and long process, each point of achievement need appropriate tasks and strategies (Larrotta, 2011).

\section{Some suggestions}

Some studies shows that there are several techniques under both strategies that focus on knowing and understanding the words and that also give opportunities for looking at the context for word meanings. Vocabulary building can be done through building personal glossaries to learn new words and their vocabulary (Larrotta, 2011). Vocabulary learning can use materials that are completely new to the learners at a higher level than the students are (Block \&Mangieri, 2006). With this kind of materials learners are forced to learn beyond what they know; therefore, helping them to grow their vocabulary.

At this level, however, some kind of scaffolding in the learning process is necessary so as to keep the learners' confidence. In general, the focus of vocabulary learning should be on knowing the meaning at the same time using them. While, integration with reading class is not impossible. This action should guarantee that the reading text should be the vehicle for learning words and the context demonstrate how the words are functioned to give a certain kind of meaning.

\section{Conclusion}

It can be concluded from the study that although there is a positive relationship between vocabulary mastery and reading performance, the relationship is not a strong one. From strength of association check, only $14 \%$ of both sets of data overlap. It means that only four students who actually make use of vocabulary knowledge in reading text.

The learning strategy and the learning materials are supposed to be the cause of this result. The learning strategy is focused more on knowing words rather than on using the words acquired, which can be done through reading. While the learning materials are mostly related to sentences as examples of how the words are used, they do not give a wider context of how words mean and how some words may mean differently from the meaning gain in the limited context as in sentences.

It is possible that vocabulary learning is integrated to the reading class; although separated class is also possible with more learning materials presented through reading texts. What is important in this regard is a consideration that vocabulary learning is fundamental in reading performance and in language learning in general, especially for L2 learning. This, then, needs a consideration that vocabulary learning should have a central role in the 
curriculum, which entails facilitation of appropriate resources such as longer learning time slot, proficient teachers, and rich learning materials.

\section{References}

AlQahtani, M. (2015).The importance of vocabulary in language learning and how to be taught.International Journal of Teaching and Education, vol III(3), pp. 21-34

Alves, B.M.L. and de Oliviera, F.M. (2014).Vocabulary acquisition in second language.International Journal of Humanities and Social Sciences, vol. 14, (13), pp. 5156

Block, C.C. and Mangieri, J.J. (2006). Powerful vocabulary for reading success. New York: Scholastic, Inc.

Browne, C. (2003). Vocabulary acquisition through reading, writing and tasks: A comparison. A dissertation.

Burkhour, H. (1999). The relationship between vocabulary and reading comprehension in junior high aged students with learning disabilities.Master theses. Paper 534

Butler, S., Urrutia, K., Buenger, A., Gonzales, N., Hunt, M., and Eisenhart, C. (2010).A review of the current research on vocabulary instruction. National Reading Technical Assistance Center (NRTAC). US Department of Education

Glende, L. (2013). Vocabulary and word study to increase comprehension in context areas for struggling reader. Education Masters. Paper 247

$\mathrm{Gu}$, P.Y. (2003). Vocabulary learning in a second language: person, task, context and strategies. The Electronic.Journal for English as a Second Language (TESL-EJ), vol. 7 (2), pp. $10-25$

Hatch, E. and Lazaraton, A. (1991).The research manual. Design and statistics for applied linguistics. New York: Newbury House Publishers

Krashen, S. (2013). Reading and vocabulary acquisition: Supporting evidence and some objections. Iranian Journal of Language Teaching Research (IJLTR), vol. 1(1), pp. 27 43

Larrotta, C. (2011). Second language vocabulary learning and teaching.Journal of Adult Education, vol. 40, pp. 1-11

Mehring, J.G. (2015). Developing vocabulary in second language acquisition: From theories to classroom.[Online]. Available at: www.cambridge.org/elt/

Downloaded on 5/12/16 at 14:30

Nagy, W.E. (1988). Vocabulary instruction and reading comprehension. Center for the Study of Reading: University of Illinois at Urbana-Champaign

Purcell-Gates, V. (1997). There's reading... and there's reading. Process model and instruction.[Online]. Available at: http://gsweb.harvard.edu/ ncsall/fob/1997/vpg.htm

Qian, D. (2002). Investigating the relationship between vocabulary knowledge and academic reading performance: An assessment perspective.Language learning, vol 52 (3), pp. 513 536

Zhang, L.J. and Suaini bin Annual (2008). The role of vocabulary in reading comprehension.RELC Journal, vol. 39 (1), pp. 51-76 